\title{
THE COMPARATIVE NONARBITRARINESS NORM OF BLAME
}

\author{
Daniel Telech and Hannah Tierney
}

$\longrightarrow$

LAME IS GOVERNED by a range of norms. Most centrally, blame is subject to a norm of correctness or fittingness. Understood as a retrospective response that represents its target as being blameworthy for (typically) an action, blame can be appropriate only if it correctly represents the blamee. Blame's fittingness thus requires that the blamee in fact be blameworthy (and that the blame be proportionate to his blameworthiness). ${ }^{1}$ The blamer must also be justified in believing that the blamee is blameworthy, otherwise the epistemic

1 For the purposes of this paper, we do not distinguish between blame being fitting and blame being deserved, where desert is generally, but not always (Nelkin, "Accountability and Desert"; King, "Moral Responsibility and Merit"), understood to be a more robust relation than fittingness. In order for blame to be fitting, as we employ the term, the target of blame must be blameworthy in a backward-looking way, leaving aside what exactly this "worthiness" comes to. So understood, this norm of blame is rejected only by those who understand blame to be a forward-looking phenomenon, evaluated as appropriate relative to its anticipated effects, e.g., of deterrence (Nowell-Smith, "Freewill and Moral Responsibility"; Smart, "Free-Will, Praise and Blame"). Thus, the debate over the fittingness norm focuses not on its existence, but its nature. For a relatively recent range of views on what it is, or at least is necessary, for blame to be fitting in this broad sense, see Arpaly, Merit, Meaning, and Human Bondage; Carlsson, "Blameworthiness as Deserved Guilt"; Darwall, The Second-Person Standpoint; Fischer and Ravizza, Responsibility and Control; Graham, "A Sketch of a Theory of Moral Blameworthiness"; Haji, Moral Appraisability; Hieronymi, "The Force and Fairness of Blame"; Kane, The Significance of Free Will; Levy, "The Good, the Bad and the Blameworthy"; Mele, "Moral Responsibility for Actions"; McKenna, Conversation and Responsibility; Nelkin, Making Sense of Freedom and Responsibility, esp. ch. 1; Pereboom, Living without Free Will, esp. chs. 2-4; Rosen, "The Alethic Conception of Moral Responsibility”; Russell, "Responsibility and the Condition of Moral Sense"; Scanlon, What We Owe to Each Other; Shoemaker, Responsibility from the Margins; Sher, In Praise of Blame, chs. 3-4; Smilansky, Free Will and Illusion; Smith, "Responsibility for Attitudes"; Strabbing, "Accountability and the Thoughts in Reactive Attitudes"; Talbert, "Moral Competence, Moral Blame, and Protest"; Vargas, Building Better Beings; Wallace, Responsibility and the Moral Sentiments, esp. chs. 6-7; Watson, "Two Faces of Responsibility"; Wolf, Freedom within Reason. 
norm of blame is flouted. ${ }^{2}$ And, even if the target of blame is blameworthy and the blamer is justified in believing them to be so, blame may still be inappropriate in virtue of violating a norm governing the moral "standing" to blame. ${ }^{3}$ For example, if an agent blames another for a wrong that they themselves have performed and have refused to acknowledge and apologize for, or if they were instrumental in the blamee's doing that for which he is blameworthy, then the agent may lack the standing to blame. A great deal has been written about these aforementioned norms, and each plays an important role in accounting for the ethics of blame. ${ }^{4}$

In this paper we argue that there exists another norm of blame that has yet to receive adequate philosophical discussion and without which an account of the ethics of blame will be incomplete: a norm proscribing comparatively arbitrary blame. ${ }^{5}$ Even when blame is fitting, is epistemically justified, and the blamer has

2 See Coates, "The Epistemic Norm of Blame," for an outline and defense of this norm, and Rosen, "Skepticism about Moral Responsibility," for a skeptical argument concerning the practical satisfiability of this kind of norm.

3 See Cohen, "Casting the First Stone"; Duff, "Blame, Moral Standing and the Legitimacy of the Criminal Trial"; Edwards, "Standing to Hold Responsible"; Fritz and Miller, "Hypocrisy and the Standing to Blame"; Herstein, "Understanding Standing"; Radzik, "On Minding Your Own Business"; Russell, "Selective Hard Compatibilism”; Smith, "On Being Responsible and Holding Responsible"; Todd, "A Unified Account of the Moral Standing to Blame"; Wallace, "Hypocrisy, Moral Address, and the Equal Standing of Persons." For critical discussion, see Bell, "The Standing to Blame."

4 There may be further norms governing the expression of blame. Fricker, for example, argues that expressions of blame "must be properly geared to people's entitlement to take some risks in learning how to do things for themselves and make their own mistakes" ("What's the Point of Blame?" 168). For further discussion of the norms of expressed blame, see Friedman, "How to Blame People Responsibly"; McGeer, "Civilizing Blame”; McKenna, Conversation and Responsibility; Scanlon, "Interpreting Blame"; Wertheimer, "Constraining Condemning."

5 However, similar norms have been discussed in other contexts. For example, in a recent paper, Kyle Fritz and Daniel Miller argue that the morally objectionable nature of hypocritical blame is grounded in the unfairness of regarding morally equal persons unequally ("Hypocrisy and the Standing to Blame"). They argue: "If $R$ ought to regard $S$ in some way, then, if there are no morally relevant differences between $S$ and some other person $T, R$ also ought to regard $T$ in this way" ("Hypocrisy and the Standing to Blame," 122-23). This bears similarity to the norm we defend in this essay with two important differences. First, we argue only that there is a nonarbitrariness norm that governs blame. In fact, in section 1 we argue that comparative arbitrariness does not render many forms of regard morally objectionable, though it does so for blame. Second, Fritz and Miller argue that comparative arbitrariness undermines an agent's standing to blame ("Hypocrisy and the Standing to Blame," 132-33). In contrast, we argue that the comparative nonarbitrariness norm is distinct from standing conditions. Here we align with Patrick Todd's criticism of Fritz and Miller and agree that an agent can blame arbitrarily, and thus objectionably, without losing their standing to blame 
the standing to blame, blame may be inappropriate in virtue of being comparatively arbitrary. That is, even when the above norms of blame are satisfied, there remains something morally objectionable about a state of affairs in which an agent blames two individuals to significantly different degrees for actions that do not ultimately differ in normative significance.

The relative absence of a comparative nonarbitrariness norm in the moral-responsibility literature is somewhat surprising given that criminal law theorists have paid a good deal of attention to parallel questions about (inter alia) the criteria for, and limits to, comparatively nonarbitrary criminal sanctioning. ${ }^{6}$ Whatever the reason for this inconspicuousness, by making explicit and defining our commitment to a norm against comparatively arbitrary blame, we stand to acquire a richer understanding of the ethics of blame and of the norms of moral responsibility more broadly. We proceed as follows. In section 1, we present a comparative nonarbitrariness condition on blame, or the "comparative condition" (cC) for short. In section 2, we address two objections that threaten cC's explanatory power: the objection from fittingness and the objection from forward-looking considerations. In section 3, we consider whether Cc can be applied interpersonally, and argue that $\mathrm{CC}$ is best conceived of as a purely intrapersonal norm. Finally, in section 4, we bring things to a nonarbitrary conclusion by reflecting on the work $\mathrm{CC}$ can do by being added to an ethics of blame.

\section{THE COMPARATIVE CONDITION}

Imagine that a parent's two adult children conspire to steal $\$ 10,000$ from her bank account. The parent blames both children, but to significantly differing degrees: she gives one child a stern talking-to and demands that they repay her $\$ 5,000$ but gives the other child only a stern talking-to. ${ }^{7}$ We stipulate that both the adult children stole their parent's money freely and are blameworthy for doing so. Additionally, the parent justifiably believes that both children engaged in this blameworthy behavior. We can also assume that the parent successfully meets all standing conditions on blame. Thus, in this case, all extant fittingness,

(Todd, "A Unified Account of the Moral Standing to Blame," 24-25). In this paper, our aim is to identify the conditions under which an agent's blame is comparatively arbitrary and incorporate a norm against this behavior into our ethics of blame.

6 E.g., Murphy, "Mercy and Legal Justice”; Husak, "Already Punished Enough”; Kolber, "The Comparative Nature of Punishment."

7 We focus on overt acts of blame in order to exemplify the practical significance of blaming to significantly differing degrees and do not presuppose that blame consists in overt actions (rather than, say, negative reactive attitudes). 
epistemic, and standing conditions for blame are met. But there is something deeply inappropriate about the parent's response to her children.

When blame is at issue, like cases must be treated alike-if the parent blames one child by demanding partial repayment, then, ceteris paribus, she should blame the other child to the same extent. Of course, it is possible that these are not like cases. There could be relevant differences between the children that justify the parent's pattern of blaming behavior. Perhaps one of the children was pressured into stealing the money by the other child (and for this reason is less blameworthy), or perhaps the parent abandoned one of the children at birth such that she does not have the appropriate relationship to blame them in the same way she blames her other child. But if the two children are guilty of the same offense to the same degree and the parent relates to both children and their wrongdoings in the same way, then it would be morally objectionable to blame them to substantially different degrees. To do so, as the parent in our example does, is to blame in a way that is comparatively arbitrary and thus pro tanto inappropriate. $^{8}$

To capture the intuition that comparatively arbitrary blame is inappropriate,

8 Factors extraneous to the norms of blame may affect whether one has all-things-considered reason to blame in a particular manner, and so whether one's blame is on balance appropriate. If, for instance, a malicious observer was to kill an innocent person unless the parent blames one child to a significantly greater degree than the other, the parent may have all-things-considered reason to blame the children to significantly different degrees. Or, perhaps due to the children's psychologies, blaming them in this way generates the best outcome. Although forward-looking factors of this sort are practically relevant to determining whether one has all-things-considered reason to blame in a certain way, factors of this type may affect one's all-things-considered reasons for any kind of response. Since our goal is to understand the factors specific to blame that render it appropriate, we put aside extraneous forward-looking considerations. But one might argue that these considerations are far from extraneous. Perhaps these forward-looking considerations can render blame nonarbitrary. In one sense, if the parent has all-things-considered reason to blame in this way, then the blame cannot be arbitrary since she has reason to do it. But in another, more pertinent sense, the parent's blame remains arbitrary in virtue of violating CC (see below). Imagine that one child is deterred from future immoral behavior more effectively if he witnesses others being blamed harshly than if he is blamed harshly, and this is why the parent has all-things-considered reason to blame her children to significantly different degrees. In this case, it might be permissible for the parent to blame them to different degrees, but this is intuitively because the bad-making feature of this kind of blame is outweighed, rather than extinguished, by the forward-looking considerations. This distinction is relevant in making sense of the moral residue that blame of this kind is apt to leave behind, e.g., the parent's regret that she had to blame in such a way as to secure the best outcome; the resentment of the harshly blamed child toward the parent; the guilt (or gratitude, or both) of the leniently blamed child upon learning of the burden borne by his sibling. 
we propose that our responsibility practices display sensitivity to the comparative nonarbitrariness condition of blame, or the "comparative condition": 9

CC: If $A$ blames $B$ for some action $X$ to a sufficiently greater (or lesser) degree than $A$ blames $C$ for $X$, and there is no morally relevant difference between either (i) $B$ or C's relationship to $X$ or (ii) A's (moral or epistemic) standing relative to $B$ or $C$, then $A$ 's blame of $B$ and $C$ is inappropriate in virtue of being comparatively arbitrary. ${ }^{10}$

Each of the two kinds of "morally relevant" differences_(i) and (ii) - is capable of justifying a significant differential in blame. B's relationship to the action $X$ may differ from C's relationship to $X$ in a morally relevant way if $B$ 's performance of $X$ requires a substantially greater degree of effort, say, or is expressive of a poorer quality of will. In this case, $B$ may be the fitting target of a greater degree of blame than $C$, and so $A$ 's blame differential will not be normatively arbitrary. Similarly, if $A$ is complicit in $B$ 's, but not $C$ 's, wrongdoing, then $A$ might lack (or have diminished) moral standing to blame $B$. In this case, because there is a normatively relevant difference in $A$ 's moral standing relative to $B$ and $C$, the blame differential might be justified. Finally, if $A$ 's epistemic situation relevantly differs with respect to $B$ 's and $C$ 's wrongdoings (perhaps $A$ has decisive evidence that $B$ acted culpably while possessing only weak evidence regarding $C$ 's culpability), then a differential in A's blame will not be comparatively arbitrary. In short, $\mathrm{CC}$ is violated when the differential in blame is explained neither by B's and C's relation to the action nor by $A$ 's (moral or epistemic) standing to blame $B$ and $C$.

In virtue of what, however, is CC-violating blame objectionable? One might suppose that it is objectionable in virtue of violating a general norm against the arbitrary treatment of persons, one requiring that we treat morally like individuals alike. If that is the case, one could explain why arbitrary blame is morally objectionable without reference to a blame-specific norm, like cc. ${ }^{11}$ This proposal, however, is without promise. In many areas of life, it is permissible to treat rele-

9 It is possible that there exists a comparative nonarbitrariness condition on praise as well. But in order to present our argument as clearly and concisely as possible, we focus exclusively on comparatively arbitrary blame. nonnormative. This is because $\mathrm{CC}$ is a claim only about the relationship between normative categories. CC claims that there ought to be no difference in our blame responses without a corresponding difference in the blameworthiness of agents or the (moral and epistemic) standing of the blamer. Thus, cc could still be true even if supervenience does not hold between the normative and nonnormative. 
vantly similar individuals dissimilarly. We can confide in, become friends with, fall in love with, and marry one individual without treating relevantly similar individuals in the same way. Now, one might rightly be disappointed when one learns that an individual who shares all their relevant features has been confided in, befriended, fallen in love with, or married to someone who has not treated them in a similar way. But, though perhaps disappointing, there need not be anything morally objectionable about such treatment; agents, even morally good agents (even those no worse than those dear to us), do not, as such, have a claim or right to our confidences, friendship, love, or hand in marriage. ${ }^{12}$ For this reason, these and other related practices and patterns of concern permissibly admit of significant degrees of arbitrariness. ${ }^{13}$ But this is not so for blame. Blame is governed by a set of norms different from those applicable to the above-mentioned forms of treatment.

Why should blame be special in this way? This is plausibly because we have a right or claim on others not to be harmed without reason, and blame characteristically imposes some (not insignificant) amount of harm on its targets. An idea common to many views of blame is that blame characteristically adversely affects the interests of-or harms - the blamee. ${ }^{14}$ Even if blame does not necessarily harm the blamed (e.g., if the blame remains unexpressed, or if the blamee is indifferent to others' evaluations and actions), there is a more than accidental connection between blame and harm. Blame is characteristically manifested in negative modes of expression and treatment, like "avoidance, reproach, scolding, denunciation, remonstration, and (at the limit) punishment." ${ }^{15}$ It is in virtue of this connection between blame and harm that responsibility theorists sometimes claim that blame responses involve liability to sanctions, or at least sanction-like responses. ${ }^{16}$ In our central case, the burdensome or sanction-like nature

On this point, see Scanlon, “Interpreting Blame," 91, and Darwall, The Second-Person Standpoint, 120.

Of course, we do not wish to claim that blame is the only practice that is governed by a comparative nonarbitrariness norm. Rather, our claim is that there is no general norm against arbitrariness that could supplant CC. But, importantly, even if this general norm did exist, CC could still do normative work. After all, what makes a practice objectionably arbitrary will differ from practice to practice. Cc specifies the conditions under which blame, in particular, is arbitrary and thus morally objectionable - i.e., by violating conditions (i) and (ii).

4 Feinberg, Harm to Others; McKenna, Conversation and Responsibility, 134-41; Rosen, "Skepticism about Moral Responsibility”; Watson, “Two Faces of Responsibility”; Wallace, Responsibility and the Moral Sentiments; Carlsson, "Blameworthiness as Deserved Guilt"; Bennett, “The Varieties of Retributive Experience," 151-52.

Wallace, Responsibility and the Moral Sentiments, 54 .

As Gary Watson writes, "Holding accountable ... involves the liability to sanctions," as 
of blame is evident, as the demand to repay $\$ 5,000$ and being the target of a condemnatory lecture both typically adversely affect one's interests.

In light of blame's sanction-like nature, together with our right or claim not to be harmed without sufficient reason, blame can be unfair. Indeed, blame can be unfair in a variety of ways. Theorists of responsibility have focused on the ways that blame might be non-comparatively unfair, as blame would arguably be if it turned out we were the sorts of agents who lacked the kind of free will, or control over our actions, necessary to be morally responsible. If we were the sorts of agents who lacked the requisite capacities (whatever they are) to be the fitting objects of blame, then, even if everyone was blamed to the same degree for the same kinds of actions, the blame might nonetheless be unfair, in a non-comparative sense. ${ }^{17}$ The same can be said for blame that violates the epistemic and standing conditions that govern our blaming practices. But CC-violating blame is unfair in a different way; it is comparatively unfair, as it relies on a significant differential in blame directed toward multiple agents who are relevantly similar. ${ }^{18}$ In our central case, the parent meets both the standing and epistemic conditions on blame, and each child is blamed to a fitting degree, so there is nothing non-comparatively unfair about the parent's blame. But the parent's blame of her children is nonetheless comparatively unfair. For, in blaming one child with

"blaming responses (at least potentially) affect the interests of their objects adversely" ("Two Faces of Responsibility," 275-80).

17 This is the type of unfairness Hieronymi discusses in considering the idea that "blaming a wrongdoer can be unfair because blame has a characteristic force, a force which is not fairly imposed upon the wrongdoer unless certain conditions are met-unless, e.g., the wrongdoer could do otherwise, or is able to control her behavior by the light of moral reasons, or played a certain role in becoming the kind of person she is" ("The Force and Fairness of Blame," 115).

18 Note that CC is not a general norm against comparatively unfair blame. There are possible ways for blame to be comparatively unfair that do not constitute violations of cc. Some argue, for example, that it is comparatively unfair to blame a person who actually does wrong but to abstain from blaming the person who would have performed the same wrong in different circumstances but did not, when the difference between the two agents is explained by a difference in their respective circumstances, which are beyond their control. This is a case of "luck in circumstances," or circumstantial luck (Nagel, "Moral Luck," 33). Opposition to this form of luck, and moral luck generally, often proceeds from the claim that it would be comparatively unfair to blame two agents differently on the basis of factors beyond their control. Comparing two such agents, Zimmerman claims that "since what distinguishes them is something over which they had no control ... it is unfair to blame [one] more than the [other]" (An Essay on Moral Responsibility, 136). We take no stand here on whether such blame is objectionable. Regardless, it does not violate $\mathrm{CC}$, as CC deals only with cases where agents in fact perform the same action. cc specifies one way of blaming that involves comparative unfairness. 
a stern talking-to plus the demand of repayment and the other with only a stern talking-to, the blamer burdens the former to a significantly greater degree, in effect giving less weight to one of the children's claims not to be harmed without sufficient reason. As such, the more severely blamed child is treated comparatively unfairly. We contend that it is in virtue of being comparatively unfair in this way that CC-violating blame is pro tanto morally wrong. ${ }^{19}$

To conclude this section, we highlight two aspects of CC that might not be immediately transparent. First, $\mathrm{CC}$ targets cases in which $A$ 's blame of $B$ and $C$ differs to a sufficiently great degree. It may be that some differentials in blame are too miniscule to make a normative difference. Or, perhaps even the smallest differential of blame is sufficiently great. We take no stance on this issue. Second, in saying that $A$ 's blame of $B$ and $C$ is inappropriate, we secure CC's status as an essentially comparative norm. That is, if $A$ arbitrarily blames $B$ to a sufficiently different degree than she blames $C$, the inappropriateness of A's blame does not reside simply in the degree to which $A$ blames $B$ or the degree to which $A$ blames $C$. This is because it is possible that, when considered non-comparatively, $A$ 's blame of $B$ is appropriate and $A$ 's blame of $C$ is appropriate. If so, the inappropriateness of $A$ 's blame of $B$ and $C$ can only be understood comparatively. We explore this thought below in replying to the objection from fittingness.

\section{THE EMPTINESS OBJECTIONS}

In this section we address two objections that, if sound, would render CC explanatorily epiphenomenal: the objection from fittingness and the objection from forward-looking considerations. According to the former, fittingness can do all the normative work to explain why comparatively arbitrary blame is morally objectionable, while the latter contends that forward-looking considerations alone can account for its objectionableness.

\subsection{The Objection from Fittingness}

One might argue that $\mathrm{CC}$ does not do any independent normative or explanatory

19 Alternatively, one might propose that the objectionableness of comparatively arbitrary blame consists in a vice manifested in the blamer. But, while it is possible that individuals who blame arbitrarily are manifesting a vice, this need not be the case; an agent's blame can violate $\mathrm{CC}$ without reflecting a vicious character. In such cases, the comparatively arbitrary blame would intuitively still be ( pro tanto) inappropriate, indicating that the relevantly objectionable feature of comparatively arbitrarily blame resides in the arbitrariness of the blame, not the blamer's character. This point sets us further apart from Fritz and Miller, who locate the morally objectionable feature of hypocritical and arbitrary blame in the dispositions of the blamer ("Hypocrisy and the Standing to Blame"). 
work. After all, morally like cases share morally relevant intrinsic features, and so perhaps the fittingness conditions that supervene on these features will, all by themselves, guarantee that like cases should be treated alike. If so, fittingness norms alone can explain what is wrong with comparatively arbitrary blame. But if norms of fittingness do all the normative work, then even if CC issues the right verdicts, it will be normatively and explanatorily epiphenomenal.

To develop this objection, let us return to the case of the adult children embezzling $\$ 10,000$ from their parent. Recall that the parent blames one child by giving them a stern talking-to and demanding that they repay her $\$ 5,000$, and blames the other child by only giving them a stern talking-to. Given that the blamer has qualitatively identical (or identical in every morally relevant respect) relations to each of the children and is equally justified in believing that each child is equally culpable, there is something deeply inappropriate about one child getting a stern talking-to and the other child getting a stern talking-to and the demand to make a $\$ 5,000$ repayment for performing the same blameworthy act. One might, however, doubt that we need cc to tell us why this is so.

The proponent of the objection from fittingness can propose an alternative explanation: the same degree of blame is fitting for both embezzlers, and the norm of fittingness provides a sufficient normative basis for the claim that one of the embezzlers is blamed objectionably. We can stipulate that both agentsAgent 1 and Agent 2-are motivated to the same degree by the same morally dubious reasons to steal their parent's money, and that the contents and strengths of all the attitudes relevant to their (equally bad) actions are qualitatively identical. Suppose " $\phi 5$ " designates the type of action they each perform, and that an agent who performs $\phi_{5}$ is the fitting object of blame to degree $D_{n}$. Since Agent 1 and Agent 2 each performs action $\phi_{5}$, they are each fitting objects of blame to degree $D_{n}$. Now, it will indeed be inappropriate if Agent 1 receives blame to degree $D_{n}$, while Agent 2 receives blame to degree $D_{n-1}$. But, the objector continues, this is explained not by some independent norm regarding comparative nonarbitrariness, but simply by the fact that Agent 2 receives less blame than is fitting. So, even if $\mathrm{CC}$ issues the right verdict regarding Agents 1 and 2, if all the normative work is done by the internal features of the case and the respective fittingness conditions, reference to cC will be normatively otiose. ${ }^{20}$

The problem with the above explanation, we contend, is its presupposition that for any given blameworthy action there is a unique degree of blame that is 
fitting. This presupposition is neither widely shared in the responsibility literature nor is it independently plausible. CC earns its keep partly because the fittingness conditions of blame generally license a spectrum of appropriate responses. This "spectrum thesis" has been implicit in the above discussion, and it will be worthwhile to provide some motivation for it. ${ }^{21}$

The falsity of the spectrum thesis (i.e., the truth of the "uniqueness thesis") would require that for each blameworthy action type there is a single, unique degree of blame that is fitting as a response. If there were a unique degree of blame that was alone fitting for any given blameworthy type of action, then the margin for fitting blame would be extremely narrow. But intuitively there are a variety of ways to appropriately blame someone who is blameworthy. In response to the same slight, one person might angrily confront the slighter, another may temporarily distance himself from the slighter, and yet another might privately resent the slighter. Should we think that, just because they differ in degree, two or perhaps all of these responses are unfitting? The uniqueness theorist is committed to this exceedingly strong claim. While there will surely be an upper threshold past which one's blame will be excessive (and often a lower threshold beneath which one's blame may be objectionably lenient), there is intuitively a bounded range of fitting responses for any given blameworthy action. ${ }^{22}$

The spectrum thesis is intuitively true of many responses beyond blame. Our responses of gratitude, regret, disappointment, trust, pride, admiration, fear, amusement, hope, and frustration (among many others) are evaluable for fittingness. And when any such response would be fitting, there will normally be several qualitatively distinct ways of fittingly reacting with a response of that type. To illustrate, consider the implausibility of a uniqueness thesis as applied to fitting responses of comic amusement. ${ }^{23}$ If there were a uniquely fitting degree of

21 A spectrum thesis for deserved blame finds explicit support in Sommers, who claims "We maintain that there is a range of appropriate blame or punishment responses and that responses outside of this range would be undeserved. Whether the betrayed spouse asks for a trial separation, files for divorce, gives the partner another chance is largely up to her. All of these are proportionate responses. But imprisoning the spouse or killing him or even cutting off all access to the children would be disproportionate" (Sommers, "Partial Desert," 255-56).

Notice that the spectrum thesis of fitting blame is presupposed by a common view of forgiveness as discretionary or elective (Allais, "Wiping the Slate Clean" and "Elective Forgiveness"; Calhoun, "Changing One's Heart”; Cowley, "Why Genuine Forgiveness Must Be Elective and Unconditional"). On this view, there is nothing morally suspect in one agent's forgiving a wrongdoer (and as such, forswearing blame) whom another blamer continues to blame, and as such, blames to a greater extent than does the forgiver.

23 The analogy between humor and responsibility has been explored recently by David Shoemaker ("Response-Dependent Responsibility") and Patrick Todd ("Strawson, Moral Re- 
comic amusement for any particular joke, then, given the wildly varying degrees of laughter in comedy clubs and movie theaters, most (and perhaps all) responses to jokes would be unfitting. But surely the norms surrounding humor permit a wide range of fitting responses to things that are funny. It would be jarring to witness a large group of individuals responding with exactly the same degree of amusement to a joke or humorous story. We take it that the same would be said of a group of individuals who blamed a blameworthy agent to exactly the same degree. The point here does not depend on the assumption that blame functions just like amusement or other fitting reactions. We are likely to be more permissive about the range of fitting responses to jokes than we are about the range of fitting responses to moral wrongs. Nevertheless, it would be surprising if instead of simply displaying a more restricted range of fitting responses, it turned out that blameworthiness did not actually warrant ranges of fitting responses at all.

Let us return to the embezzling adult children case. What is wrong with this case is not that one agent received too little blame or that the other agent received too much-(i) stern talking-tos and (ii) stern talking-tos in addition to demands for partial repayment are both appropriate ways of blaming such acts of embezzlement. It would be appropriate if the parent gave both children stern talking-tos and demanded that each child pay her $\$ 5,000$ or only gave both children stern talking-tos, for example. It is only by invoking a relational or comparative norm like CC that we can identify what is inappropriate about the parent's blaming one of their children in manner (i) and the other in manner (ii). Although both instances of blame are fitting, there is more to appropriate blame than fittingness (and epistemic justification, and standing). Given that there is no relevant difference in the parent's beliefs about each child's culpability, her relationships to the two children, or between the children's relationships to the blameworthy actions they perform, if one child receives (i) and the other (ii), we have reason to conclude that the disparity in strength of blame is inappropriate in virtue of being comparatively arbitrary. Thus, norms of fittingness do not render Cc normatively otiose.

\subsection{The Objection from Forward-Looking Considerations}

Even if fittingness cannot, all by itself, provide an explanation for the objectionableness of comparatively arbitrary blame, perhaps other explanations are available. In particular, one might think that a forward-looking explanation can provide a suitable alternative to Cc. Our opponent might maintain that our

sponsibility, and the 'Order of Explanation'”) in the development of response-dependence accounts of responsibility. 
blaming responses are subject to a (backward-looking) norm of fittingness, but that there are also forward-looking reasons for blame to appear fitting, both to the blamees and to observers. For if our blame responses appear arbitrary (as they sometimes will when two agents are blamed to different, but fitting, degrees), blame may lose some of its deterrent or rehabilitative efficacy. ${ }^{24}$ Perhaps if blamees and the moral community generally had all the relevant information, and so understood that seemingly comparatively arbitrary instances of blame were really different-but-fitting instances of blame, then there would be no problem with blaming in different-but-fitting ways. But observers and recipients of our blaming responses typically do not have all the relevant information, and often will not understand that seemingly arbitrary instances of blame are only seemingly arbitrary. To avoid appearances of arbitrariness, then, we should blame wrongdoers to the same fitting degree.

In response, we grant that there may be forward-looking reasons for our blaming responses not to appear arbitrary. But it is not plausible that forward-looking considerations are the only (or even the primary) reasons not to blame wrongdoers to different degrees. For, even in cases where the blamees will acknowledge that each of the blame responses is fitting, we contend that they will still find it morally objectionable that one is blamed more severely (and so has his interests more adversely affected) than the other. The following strikes us as a reasonable response that the more severely blamed person may issue: "Yes, but why should I be blamed more severely?" This sort of reaction will be available to them even if they realize that both instances of blame were fitting. A parent might believe that each of the following is a fitting response to a child's breaking curfew: (i) grounding the child for a night; (ii) verbally communicating disapproval and giving the child a second chance. But, thinking back on some occasion when, as a teenager, he (i.e., the parent) was grounded while his sibling was merely scolded for breaking curfew, he may continue to believe that there was something objectionable - indeed, unfair —in his being blamed more severely than his sibling.

The forward-looking reasons for blame to appear nonarbitrary are likely derivative of the backward-looking reasons against comparatively arbitrary blame. To illustrate, consider a similar forward-looking explanation of the wrongness of hypocritical blame. One might hold that if the blamee is indeed a fitting target of blame, hypocritical blame (i.e., blame issued by a blamer who is unapologetically guilty of the same offense for which he blames another) is not objectionable in itself. But as the blamee is likely to be defensive when he is blamed by another who unapologetically commits the same wrong, such blame is unlikely to be ef-

24 We are thankful to an anonymous reviewer for raising this objection. 
fective (and may even be counterproductive). Although it is true that this sort of blame is unlikely to be effective, this is intuitively because it is morally objectionable in itself. In replying, "Who are you to blame me?" the blamee is not merely deflecting blame, but voicing a reasonable objection about the prerequisites for having the standing to blame. So while there is plausibly a forward-looking reason not to blame hypocritically, this reason is parasitic on the backward-looking reason that hypocritical blame is objectionable in itself. Likewise, comparatively arbitrary blame is less likely to be effective at promoting rehabilitation and deterrence, but we contend that this is chiefly because comparatively arbitrary blame is unfair in itself. In our view, the forward-looking reasons to not blame in comparatively arbitrary ways are thus parasitic on the backward-looking reason against arbitrary blame. ${ }^{25}$

\section{WHY IS CC AN INTRAPERSONAL BUT NOT INTERPERSONAL NORM?}

We have presented $\mathrm{CC}$ as an intrapersonal norm that governs an agent's blame of other, equally blameworthy agents. But one might wonder whether CC can be applied interpersonally as well. That is, can cc constrain how distinct blamers blame individuals who have committed similar wrongs?

Imagine that two different, unrelated parents ( 1 1 and P2) discover that each of their adult children ( $\mathrm{C} 1$ and $\mathrm{C} 2$ ) has embezzled \$10,000 from each of them. We can imagine that all the relevant facts about these two cases are the same: the adult children are equally blameworthy for stealing the money, the parents justifiably believe to the same degree that their respective children embezzled from them, and the parents relate to their children in qualitatively identical ways. If P1 blames $\mathrm{C} 1$ by giving them a stern talking-to and demanding a $\$ 5,000$ repayment, and P2 blames $\mathrm{C} 2$ by only giving them a stern talking-to, has something inappropriate occurred?

Since we think there exists a spectrum of fitting responses to a given blame-

25 There may be further forward-looking considerations relevant to blaming in a cC-consistent manner. For example, Cc-consistent blame differs from CC-violating blame in precluding worries on the part of the more severely blamed blamee that they are being discriminated against. Stipulating that the differential blame is not in fact explained by a discriminatory bias (or an otherwise pernicious property) of the blamer, it will nonetheless sometimes be understandable for blamees and observers to wonder whether they are being blamed differentially on the basis of a morally irrelevant feature (e.g., membership in a historically marginalized group). (Their so wondering is apt to give rise to negative hedonic feelings, like distress and anxiety, and so cC-violating blame can be criticized on utilitarian grounds.) Indeed, the blamee might wonder this despite knowing that the blame is non-comparatively appropriate, i.e., fitting. 
worthy action, and $\mathrm{C}_{1}$ and $\mathrm{C}_{2}$ have performed qualitatively identical blameworthy actions, we think it is perfectly appropriate for P1 to blame $\mathrm{C} 1$ by giving them a stern talking-to and demanding partial repayment and for $\mathrm{P} 2$ to blame $\mathrm{C} 2$ by only giving them a stern talking-to. After all, there is nothing morally suspect about one parent choosing to ground their child for breaking curfew and another parent choosing to simply verbally communicate their disapproval for doing the same. However, there is something inappropriate (and deeply so if you ask the children involved) about a parent choosing to ground one of their children for breaking curfew but not their other child for doing the same. In such a case, the parent gives one child's moral claim not to be harmed (without reason) greater weight than she gives the other's. Her blame is therefore comparatively unfair. We have an obligation to be consistent in our blame of others, but we do not have an obligation to render our blame in line with how others blame. Moreover, on the assumption that the spectrum thesis is true, we cannot have an obligation to blame in a way that is consistent with others, since the relevant others might themselves blame to different, but fitting, degrees. While it is possible for me to blame to the same degree that $A$ does, I cannot blame to the same degree that both $A$ and $B$ do if $A$ and $B$ blame to different (but fitting) degrees.

One could argue that though we are not required to render our blame in line with others' blame, we should hold ourselves to the same standards we think others ought to be held to. For example, imagine that P1, prior to blaming C1, learns that P2 blamed $\mathrm{C}_{2}$ by only giving them a stern talking-to. Imagine further that P1 judges P2's blame to be appropriate and thinks there are no relevant differences between their two situations. One might argue that P1 should then blame $\mathrm{C} 1$ to the same degree that $\mathrm{P} 2$ blamed $\mathrm{C} 2$. Perhaps nonarbitrariness norms like CC should not require agents to be consistent with how others blame, but they should require that blamers be consistent with their judgments about how others blame. If this is correct, then one could modify CC to capture these kinds of cases and it could still remain an entirely intrapersonal norm.

However, we would resist such revisions to CC. We contend that it is perfectly consistent for P1 to judge that P2 blames $\mathrm{C} 2$ appropriately and to judge that her own blame of $\mathrm{C} 1$ is also appropriate despite differing in degree. Just as we think there exists a spectrum of appropriate responses to blameworthy agents, we also think agents can coherently judge that distinct instances of blame are appropriate, even if they differ in degree. Of course, reflecting on what you take to be appropriate instances of blame could lead you to revise your judgments about other instances of blame and even your own blaming practices. If, upon reflection, $\mathrm{P} 1$ judges that it is appropriate for $\mathrm{P} 2$ to blame $\mathrm{C} 2$ by only giving them 
a stern talking-to, p1 might question whether their decision to demand partial repayment from C1 was really appropriate. But revisiting one's judgments about the appropriateness of an act of blame in light of how others blame is not an expression of a commitment to nonarbitrariness. Rather, it is most likely an expression of epistemic humility. These are important, but distinct, norms that we should be careful not to conflate.

While the way others blame is not irrelevant to how we ourselves ought to blame, we do not have an obligation to render our blame in line with others' blame, even if we deem it appropriate. We do, however, have an obligation to be consistent in our own blaming responses. Thus, we think CC is properly conceived of as a purely intrapersonal norm.

\section{CONCLUSION}

In this paper, we first developed a norm proscribing comparatively arbitrary blame: CC. Next, we defended CC against two charges of explanatory vacuity and then argued that it properly applies only to instances of intrapersonally arbitrary blame. We will now conclude by briefly reflecting on the importance of including $\mathrm{CC}$ in an ethics of blame.

Given the inherently social character of moral responsibility-its arena regularly referred to as that of the community of morally responsible agents-it is unsurprising that we care not only about the way in which others blame us, but also about the way others blame us relative to their blame of similar agents. Given the literature's focus on non-comparative norms of blame, it is difficult to give voice to what is wrong with blaming relevantly similar agents to different degrees. After all, it would not be right to say that such blame is unfitting or that the blamer lacks moral or epistemic standing. Cc, however, can identify what is morally objectionable about the blame in such cases: it is comparatively arbitrary, and so treats one of the blamees comparatively unfairly. As theorists of blame and responsibility are already committed to understanding the conditions under which blame is fair, they should not exclude the conditions under which blame may be comparatively unfair, especially given the inherently social character of moral responsibility. In acknowledging the moral relevance of an individual's blame of multiple agents, Cc sheds new light both on the nature of blame and on the ways in which blame can be morally objectionable. Once we are able to properly diagnose what is wrong with these blaming interactions, we are in a position to improve them. By focusing on the comparative aspects of blame, CC 
is poised to contribute to both our understanding and the improvement of the practices of blame. ${ }^{26}$

\author{
Polonsky Academy, The Van Leer Jerusalem Institute \\ danielt@vanleer.org.il \\ University of Sydney \\ hannah.tierney@sydney.edu.au
}

\title{
REFERENCES
}

Allais, Lucy. "Elective Forgiveness." International Journal of Philosophical Studies 21, no. 5 (2013): 637-53.

- "Wiping the Slate Clean: The Heart of Forgiveness." Philosophy and Public Affairs 36, no. 1 (Winter 2008): 33-68.

Arpaly, Nomy. Merit, Meaning, and Human Bondage: An Essay on Free Will. Princeton: Princeton University Press, 2006.

Bell, Macalester. "The Standing to Blame." In Coates and Tognazzini, Blame: Its Nature and Norms, 263-81.

Bennett, Christopher. "The Varieties of Retributive Experience." Philosophical Quarterly 52, no. 207 (April 2002): 145-63.

Calhoun, Cheshire. "Changing One's Heart." Ethics 103, no. 1 (October 1992): 76-96.

Carlsson, Andreas Brekke. "Blameworthiness as Deserved Guilt." Journal of Ethics 21, no. 1 (March 2017): 89-115.

Chemerinsky, Erwin. "In Defense of Equality: A Reply to Professor Westen." Michigan Law Review 81, no. 3 (January 1983): 575-99.

Coates, D. Justin. “The Epistemic Norm of Blame." Ethical Theory and Moral Practice 19, no. 2 (April 2016): 457-73.

Coates, D. Justin, and Neal A. Tognazzini, eds. Blame: Its Nature and Norms. Oxford: Oxford University Press, 2013.

Cohen, G. A. "Casting the First Stone: Who Can, and Who Can't, Condemn the Terrorists?” Royal Institute of Philosophy Supplement 58 (May 2006): 113-36.

Cowley, Christopher. "Why Genuine Forgiveness Must Be Elective and Unconditional." Ethical Perspectives 17, no. 4 (2010): 556-79.

26 We are thankful to David Enoch, Michael McKenna, and Derk Pereboom for helpful comments on earlier drafts of this essay. We would also like to thank the two anonymous referees for this journal for their extremely valuable feedback. 
Darwall, Stephen. The Second-Person Standpoint: Morality, Respect, and Accountability. Cambridge, MA: Harvard University Press, 2006.

Duff, R.A. "Blame, Moral Standing and the Legitimacy of the Criminal Trial." Ratio 23, no. 2 (June 2010): 123-40.

Edwards, James. "Standing to Hold Responsible." Journal of Moral Philosophy (forthcoming).

Feinberg, Joel. Harm to Others. Oxford: Oxford University Press, 1986.

Fischer, John Martin, and Mark Ravizza. Responsibility and Control: An Essay on Moral Responsibility. Cambridge: Cambridge University Press, 1998.

Fricker, Miranda. "What's the Point of Blame? A Paradigm Based Explanation." Noûs 50, no. 1 (March 2016): 165-83.

Friedman, Marilyn. "How to Blame People Responsibly." Journal of Value Inquiry 47, no. 3 (September 2013): 271-84.

Fritz, Kyle, and Daniel Miller. "Hypocrisy and the Standing to Blame." Pacific Philosophical Quarterly 99, no. 1 (March 2018): 118-39.

Graham, Peter. "A Sketch of a Theory of Moral Blameworthiness." Philosophy and Phenomenological Research 88, no. 2 (March 2014): 388-409.

Haji, Ishtiyaque. Moral Appraisability: Puzzles, Proposals, and Perplexities. Oxford: Oxford University Press, 1998.

Herstein, Ori. "Understanding Standing: Permission to Deflect Reasons." Philosophical Studies 174, no. 12 (December 2017): 3109-32.

Hieronymi, Pamela. "The Force and Fairness of Blame." Philosophical Perspectives 18, no. 1 (December 2004): 115-48.

Husak, Douglas N. "Already Punished Enough." Philosophical Topics 18, no. 1 (Spring 1990): 79-99.

Kane, Robert. The Significance of Free Will. Oxford: Oxford University Press, 1996.

King, Matt. "Moral Responsibility and Merit." Journal of Ethics and Social Philosophy 6, no. 2 (August 2012): 1-17.

Kolber, Adam J. “The Comparative Nature of Punishment." Boston University Law Review 89 (December 2009): 1565-1608.

Levy, Neil. "The Good, the Bad and the Blameworthy." Journal of Ethics and Social Philosophy 1, no. 2 (June 2005): 1-14.

McGeer, Victoria. "Civilizing Blame." In Coates and Tognazzini, Blame: Its Nature and Norms, $162-88$.

McKenna, Michael. Conversation and Responsibility. Oxford: Oxford University Press, 2012.

Mele, Alfred R. "Moral Responsibility for Actions: Epistemic and Freedom Conditions." Philosophical Explorations 13, no. 2 (June 2010): 101-11. 
Murphy, Jeffrie G. "Mercy and Legal Justice." Social Philosophy and Policy 4, no. 1 (Autumn 1986): 1-14.

Nagel, Thomas. "Moral Luck." In Mortal Questions. Cambridge: Cambridge University Press, 1979.

Nelkin, Dana. "Accountability and Desert." Journal of Ethics 20, nos. 1-3 (September 2016): 173-89.

- Making Sense of Freedom and Responsibility. Oxford: Oxford University Press, 2011.

Nowell-Smith, P.H. "Freewill and Moral Responsibility." Mind 57, no. 225 (January 1948): 45-61.

Pereboom, Derk. Living without Free Will. Cambridge: Cambridge University Press, 2001.

Radzik, Linda. "On Minding Your Own Business: Differentiating Accountability Relations within the Moral Community." Social Theory and Practice 37, no. 4 (October 2011): 574-98.

Rosen, Gideon. "The Alethic Conception of Moral Responsibility." In The Nature of Moral Responsibility: New Essays, edited by Randolph Clarke, Michael McKenna, and Angela Smith, 65-88. Oxford: Oxford University Press, 2015.

_- "Skepticism about Moral Responsibility." Philosophical Perspectives 18, no. 1 (December 2004): 295-313.

Russell, Paul. "Responsibility and the Condition of Moral Sense." Philosophical Topics 32, nos. 1-2 (Spring and Fall 2004): 287-305.

—_. "Selective Hard Compatibilism." In Action, Ethics and Responsibility, edited by Joseph Keim Campbell, Michael O’Rourke, and Harry S. Silverstein, 149-73. Cambridge, MA: MIT Press, 2010.

Scanlon, T. M. “Interpreting Blame." In Coates and Tognazzini, Blame: Its Nature and Norms, 84-99.

-. Moral Dimensions: Permissibility, Meaning, Blame. Cambridge, MA: Belknap Press of Harvard University Press, 2008.

-What We Owe to Each Other. Cambridge, MA: Belknap Press of Harvard University Press, 1998.

Sher, George. In Praise of Blame. Oxford: Oxford University Press, 2006.

Shoemaker, David. "Response-Dependent Responsibility; or, A Funny Thing Happened on the Way to Blame." Philosophical Review 126, no. 4 (October 2017): 481-528.

- Responsibility from the Margins. Oxford: Oxford University Press, 2015.

Simons, Kenneth W. "Equality as a Comparative Right." Boston University Law Review 65, no. 3 (1985): 387-482. 
Smart, J.J. C. "Free-Will, Praise and Blame." Mind 70, no. 269 (July 1961): 291306.

Smilansky, Saul. Free Will and Illusion. Oxford: Oxford University Press, 2000.

Smith, Angela M. “On Being Responsible and Holding Responsible." Journal of Ethics 11, no. 4 (December 2007): 465-84.

_. "Responsibility for Attitudes." Ethics 115, no. 2 (January 2005): 236-71.

Sommers, Tamler. "Partial Desert." In Oxford Studies in Agency and Responsibility, vol. 1, edited by David Shoemaker, 246-62. Oxford: Oxford University Press, 2013.

Strabbing, Jada Twedt. "Accountability and the Thoughts in Reactive Attitudes." Philosophical Studies (forthcoming).

Talbert, Matthew. "Moral Competence, Moral Blame, and Protest." Journal of Ethics 16, no. 1 (March 2012): 89-109.

Todd, Patrick. "Strawson, Moral Responsibility, and the 'Order of Explanation': An Intervention." Ethics 127, no. 1 (October 2016): 208-40.

. "A Unified Account of the Moral Standing to Blame." Noûs 53, no. 2 (June 2019): 347-74.

Vargas, Manuel. Building Better Beings: A Theory of Moral Responsibility. Oxford: Oxford University Press, 2013.

Wallace, R. Jay. "Hypocrisy, Moral Address, and the Equal Standing of Persons." Philosophy and Public Affairs 38, no. 4 (Fall 2010): 307-41.

- Responsibility and the Moral Sentiments. Cambridge, MA: Harvard University Press, 1994.

Watson, Gary. "Two Faces of Responsibility." In Agency and Answerability: Selected Essays. Oxford: Clarendon, 1996.

Wertheimer, Roger. “Constraining Condemning." Ethics 108, no. 3 (April 1998): 489-501.

Westen, Peter. “The Empty Idea of Equality." Harvard Law Review 95, no. 3 (January 1982): 537-96.

Wolf, Susan. Freedom within Reason. Oxford: Oxford University Press, 1990.

Zimmerman, Michael J. An Essay on Moral Responsibility. Lanham, MD: Rowman and Littlefield, 1988. 